\title{
PEMBELAJARAN MANAJEMEN RESIKO DALAM KETRAMPILAN BAHASA DAN BUDAYA BAGI PESERTA PROGRAM INTERNASIONAL
}

\author{
Kun Aniroh \\ Email: kun.aniroh@gmail.com \\ Program Diploma IV Pariwisata Universitas Merdeka Malang \\ Alamat Korespondensi: Jl. Tirtotaruno Gang V/No.20 Landungsari, Malang
}

\begin{abstract}
Abstrak: Risk management theoritically or practicallyis an important need for the international program particpants and for the organizer.Many campuses in Indonesia hold the Indonesian Language and Culture Program and other similarcultural programs.To face the enaction of ASEAN Economic Community next December 2015 in which one of the programs is the issuance of free visa for skilled labors, the international exchange for studying, apprenticeship, and working is becoming more intensive due to the fact that Indonesia is a potential market and is an attractive tourist destination.Therefore, risk management is a compelling need. The success of managing risk for the safety of international program participants can enhance the image of Indonesia in education, tourism, trade and other sectors. Based on the importance of risk management in including it in the language and culture skill or other similar programsin Indonesian and English as the best parctice,it is hoped to contribute in the education of minimizing disaster risks.
\end{abstract}

Key words: risk management, international program participants, learning, language and cultural skills.

\section{PENDAHULUAN}

$\begin{array}{ccc}\text { Manajemen } & \text { resiko merupakan } \\ \text { kebutuhan setiap } & \text { orang. } & \text { Dimanapun }\end{array}$ seseorang berada kewaspadaan hendaknya menjadi hal utama apalagi di tempat yang belum dikenal sama sekali baik itu berhubungan dengan daerah yang baru pertama dikunjungi maupun orang-orang baru disekitar. Seperti kata pepatah, lain padang lain belalang lain lubuk lain ikannya,yang berarti bahwa setiap daerah itu mempunyai adat-istiadat sendiri yang harus dihormati. Di jaman global sekarang ini lalu lalang orang dalam melakukan perjalanan untuk keperluan berbagai bidang semakin hari semakin banyak, baik untuk keperluan bekerja, belajar maupun berwisata. Melakukan perjalanan di luar daerahdisamping dapat mengurangi rasa stres dan lelah juga merupakan suatu 'prestise' atau aktualisasi diri termasuk aktivitas-aktivitas yang dilakukannya. Namun demikian, seseorang kadang lupa bahwa pada saat melakukan aktivitas atau sedang menikmati sesuatu yang menarik ada bahaya tersembunyi yang mengintai yang tidak disadari.

Berkaitan dengan pembelajaran bahasa dan budaya serta program-program internasional lain yang banyak diselenggarakan oleh kampus-kampus di Indonesia, mengedepankan keselamatan, kesehatan dan keamanan merupakan kebutuhan utama yang tidak tidak bisa ditawar. Hal tersebut menjadi tolok ukur bagi penyelenggara program. Keselamatan dalam hal ini meliputi keselamatan diri sendiri, kesehatan dan keselamatan akan harta benda -yang dimilikinya. Ketiga hal tersebut dapat dipelajari melalui kebiasaan yang ada dalam masyarakat setempat. Sedangkan kewaspadaan berhubungan dengan tempat 
tinggal baru, orang-orang yang baru dikenal, suasana baru, masyarakat yang baru dikenal yang semuanya berbeda dengan kondisi atau keadaan peserta di tempat asal.Sehubungan dengan hal tersebut manajemen resiko seyogyanya dipahami dengan baik oleh penyelenggara program maupun peserta program internasional.

Sehubungan dengan hal tersebut manajemen resiko seyogyanya dipahami dengan baik oleh penyelenggara program maupun peserta program internasional. Manajemen resiko adalah proses identifikasi resiko yang sedang berlangsung, menganalisa dan mengembangkan respon terhadap faktor resiko (Baltzan, Philips dan Haag, 2009,h.524 dalam Oroian, 2011.h.12)

Berdasarkan pengamatan di beberapa organisasi internasionalbencana yang sering dialami oleh para peserta programinternasional(PPI)adalah kesehatan, keamanan dan budaya. Dalam hal kesehatan ketidakcocokan makanan pada saat-saat awal merupakan hal yang banyak dialami oleh para mahasiswa sehingga menimbulkan sakit yang berhubungan dengan pencernaan. Penyakit semacam ini ada yang berlangsung sebentar tetapi juga berlangsung lama bahkan dapat menjadi lebih parah dan penderita harus diopname di rumah sakit.Menurut Posthuma, Richard dan Jaime (2008, h.3)bencana yang dialami oleh ekspat dibagi menjadi dua yaitu bencana kesehatan dan bencana keamanan. Termasuk dalam bencana kesehatan adalah wabah endemik, penyakit menular, fasilitas dan jumlah pusat kesehatan lokal yang berkualitas rendah dan sulitnya mengakses pusat-pusat kesehatan. Sedangkan termasuk dalam resiko keamanan adalah masalah terorisme, kriminalitas, dan resiko lain yang berhubungan dengan situasi politik dan sosial.Termasuk dalam bencana yang berhubungan dengan budaya adalah kurangnya kepekaan terhadap budaya setempat, menganggap segala sesuatu tidak apa-apa (poorjudgement) dan kerentanan daerah kediamanpenduduk(redidential vulnerability), dan kerentanan akan resiko harta kekayaan (poorjudgement in risking life over property). Ketidaktahuan seseorang akan budaya setempat bagi orang baru dapat menimbulkan masalah yang akan mengganggu keselamatan dan keamanan baik bagi orang baru tersebut maupun bagi masyarakat di sekitarnya.

Seiring dengan kebutuhan akan keselamatan, kesehatan dan keamanan karena perpindahan orang yang semakin tinggi, kebutuhan akan pengetahuan tentang budaya antar negara ASEAN juga meningkat, dan hal ini sudah disepakati dalam kesejahteraan dan perlindungan sosial pembangunan bangsa yang tahan bencana dan masyarakat yang lebih aman. Ada 12 tindakan yang menjadi prioritas yang salah satunya adalah memperkuat kesiapsiagaan menghadapi bencana yang berbasis masyarakat dan partisipasi melalui upaya promosi kearifan lokal dan kebiasaan setempat, implementasi kesadaran publik dan pendidikan serta pemanfaatan bersama praktik terbaik dan pelajaran yang diperoleh untuk membangun masyarakat yang tahan bencana (Cetak Biru Komunitas Sosial Budaya ASEAN 2010, h.2627 ). Dengan demikian pembelajaran tentang manajemen resiko di suatu daerah juga merupakan pembelajaran budaya.

Sehubungan dengan hal tersebut artikel ini bertujuan untuk mendeskripsikan manajemen resiko yang biasanya dihadapi oleh PPI pada umumnya baik yang berhubungan dengan kesehatan, keamanan maupun budaya dengan harapan pengelola program-program internasional dan PPI lebih sigap dalam mengambil keputusan apabila mengalami hal-hal yang tidak diinginkan.

\section{Pembelajaran Bahasa dan Budaya Indonesia}

Salah satu program internasional yang dilaksanakan di kampus-kampus di Indonesia adalah Pembelajaran Bahasa dan Budaya Indonesia(selanjutnya disebut PPBI). Program ini sudah dimulai sejak tahun 1840 yang tersebar di 37 negara antara lain di Jepang, Jerman, Amerika Serikat, Canada, Australia, Cina, Filipina, Hongkong, Singapura Taiwan dan lain sebagainya (Direktorat Ketenagaan Republik Indonesia 2008). Oleh karena itu, tidak mengherankan jika banyak kampus di Indonesia setiap tahun atau semester menyelenggarakan PBBI. Para peserta PBBI tinggal di Indonesia dalam waktu yang pendek, menengah maupun jangka panjang atau antara 2 minggu sampai satu tahun. Selama tinggal di Indonesia selain belajar di kelas mereka juga belajar di luar kelas yang 
kegiatannya mengunjungi obyek-obyek wisata alam, budaya, peninggalan sejarah, menyaksikan festival, mengikuti seminar, melakukan penelitian, menginap dirumah penduduk setempat, menghadiri acara adat setempat dan kegiatan lain yang tujuannya adalah meningkatkan kemampuan berbahasa dan mempelajari budaya Indonesia.

Disamping hal tersebut diatas perkembangan pendekatan pengajaran bahasa kini sudah memasukkan budaya yang dalam pengajaran Bahasa Inggris terkini terdapat Content Language Integrated Language Learning(CLIL) yang beberapa diantaranya bertujuan memperkenalkan konteks budaya secara lebih luas, mempersiapkan internasionalisasi, dan mengembangkan minat multibahasa dan sikapdalam berbahasa, yang kegiatannya antara lain language showers, one-week CLIL camp, international project dan total early immersion (Mehisto, Marsh and Frigols, 2012, h.13-17). Sedangkan Culture for Teaching English menyatakan bahwa bahasa bukan hanya sekedar bagaimana mendefinisikan budaya tetapi merefleksikan budaya. Budaya itu adalah konsep luas yang diturunkan pada banyak konsep bahasa yang diajarkan dalam bahasa kedua(Goode, Sockalingam, Brown and Jones, 2000 dalam Omer dan Ali 2011, h. 258).Strategi dalam mengajarkan budaya bisa menggunakan materi otentik dari masyarakat penutur berupa film, pemberitaan atau pertunjukan televisi bermain peran maupun kapsul budaya yaitu menggunakan obyek yang berasal dari budaya target. Sedangkan Tomalin (2008, h.1) menyatakan bahwa pengajaran bahasa Inggris seyogyanya memasukkan pengetahuan budaya, nilai budaya, tingkah laku budaya dan kecakapan budaya setelah kecakapan mendengarkan, berbicara, membaca dan menulis.

\section{Pembelajaran Bahasa, Budaya, Pariwisata dan Manajemen Resiko}

Dalam pariwisata, PBBI dikategorikan sebagai salah satu wisata pendidikan yang sangat potensial. Wisata ini mempunyai efek ekonomi ganda yang tinggi karena lama tinggal yang panjang (Mc.Instosch, Goeldner, and Ritchie, 1995, h. 256). Wisata yang dilakukan oleh PPBI ini dapat dikembangkan menjadi banyak diversifikasi produk bidang bahasa menjadi wisata minat khusus bahasa.
Di Malang ada bahasa Jawa ragam Malangan,misalnya bahasa Walikan yang sangat khas yang tidak dipunyai oleh masyarakat lain. Malang juga mempunyai banyak komunitas pecinta sepakbola AREMA yang mempunyai jargon-jargon tertentu yang menarik sebagai produk pariwisata. Pembelajaran Bahasa dan Budaya Indonesia (PBBI) dalam bahasa Inggris disebut Teaching Indonesian as a Foreign Language(TIFL). PBBI di berbagai kampus dapat menambahkan kekhasan bahasa daerah masing-masing sebagai sentuhan khusus yang membedakan antara PBBI di suatu daerah dengan daerah lain, sehingga akan banyak produk wisata minat khusus bahasa, misalnya TIJL( Teaching Javanese as a Foreign Language), TIWL( Teaching Walikan as a Foreign Language), Teaching Balinese as a Foreign (TIBL)dan bahasa-bahasa daerah lain yang dapat dikembangkan sebagai produk yang mempunyai nilai tambah. Dengan memasukkan bahasa Daerah sebagai tambahan PBBI banyak keuntungan yang dapat diperoleh antara lain ada usaha untuk melestarikan penggunaan bahasa Daerah, menggugah kesadaran masyarakat akan penggunaan bahasa Daerah, meningkatkan eksplorasi akan bahasa dan budayaDaerah sehingga akan menimbulkan rasa cinta tanah air melalui bahasa.

Bagi para pengajar bahasa Indonesia, bahasa Daerah maupun bahasa Inggris atau bahasa asing lainnya kerjasama dalam bidang pengajaran akan mendorong kerjasama lintas disiplin ilmu. PBBI pada tingkat awal membutuhkan bantuan bahasa Inggris atau bahasa asing lain untuk kelancaran proses belajar mengajar, demikian pula bila sudah sampai tingkat menengah atau tingkat mahir peranan bahasa asing untuk membantu kelancaran proses belajar mengajar tetap dibutuhkan, dan penggunaan bahasa Inggris lambat laun dikurangi.

Dengan berlakunya Masyarakat Ekonomi ASEAN pada tahun 2015 dan World Trade Organization pada tahun 2018kebutuhan akan PBBI akan meningkat karena dibukanya aliran barang, jasa, investasi, logistik dan sumberdaya trampil (Pidato Menteri Pariwisata Ekonomi Kreatif, Marie Elka Pangestu,dalam Munas Hildiktipari 13 Mei 2014). Indonesia merupakan potensi pasar yang sangat besar dengan jumlah 
penduduk nomor 5 di dunia. Siapapun yang akan menjalin kerjasama dengan Indonesia di bidang apapun penguasaan bahasa Indonesia merupakan salah satu kunci sukses. Ada dua kepentingan strategis dalam PBBI ini. Di satu sisi produk bahasa bisa dijual karena banyak orang diberbagai negara mempunyai kepentingan ekonomi, politik dan kepentingan lainnya. Di sisi lain sektor-sektor penting bila tidak diantisipasi sedemikian rupa dengan peraturan, maka tidak tertutup kemungkinan aset-aset akan lebih dinikmati oleh pihak asing karena mereka sudah menguasai bahasa Indonesia. Ini juga merupakan bencana bagi masyarakat sekitar.

Bencana adalah gangguan fungsi yang serius dari suatu masyarakat yang menyebabkan kerugian manusia di bidang lingkungan, ekonomi, materi yang melebihi kemampuan dan mempengaruhi masyarakat untuk menyelesaikannya dengan menggunakan kemampuan mereka (Lemmet, Silvia and Hopkin, KCMG, 2008.h.6) Dari definisi ini dapat disimpulkan bahwa masyarakat berupaya dengan menggunakan kemampuan dalam menyelesaikan gangguan yang kemungkinan terjadi pada dirinya

Manajemen resiko yang perlu dipikirkan adalah melakukan sesuatu yang diimplementasikan dalam kegiatan bahasa dan budaya untuk menjamin keselamatan diri sendiri. Kegiatan-kegiatan tersebut meliputi kegiatan sejak dari penjemputan, selama mengikuti PBBI dan setelah mengikuti PBBI. Pada saat penjemputan para pembelajar akan melewati tempat umum seperti bandara, stasiun kereta api, terminal bus atau tempat umum lainnya. Demikian pula setelah tiba di hotel atau di rumah keluarga. Pada saat keluar rumah mengikuti PBBI akan melewati jalan yang sebagian besar tidak mempunyai trotoar. Di jalan orang asing akan tampak beda penampilannya sehingga akan menjadi pusat perhatian baik dalam segi yang positif maupun negatif. Dari segi positif kampus atau tempat belajar menaikkan sisi promotif dengan kedatangan wisatawan asing namun disisi lain kewaspadaan harus ditingkatkan untuk keselamatan dan kenyamanan mereka.

\section{Penerapan Manajemen Resiko dalam Pembelajaran Bahasa dan Budaya}

PPBI dan program-program pertukaran internasional yang lain selama ini kurang memperhatikan manajemen resiko sehingga apabila terjadi sesuatu dengan PPI penyelenggara kurang sigap dan belum ada aturan-aturan tertulis yang mengikat. Hak dan kewajiban PPI dan penyelenggara diatur dengan baik, demikian pula dengan keluarga apabila PPI tinggal dengan keluarga.Pemberian informasi tentang hak dan kewajiban ini bisa dilakukan sebelum program dilaksanakan atau bisa diberikan di negara asal, diulangi lagi saat setelah PPI tiba di tempat, dan dibahas dalam matakuliah. Dengan demikian terjemahan dalam bahasa Inggris sangat diperlukan untuk dapat memahami informasi manajemen resiko ini.

Pembelajaran bahasa dan budaya tidak hanya kecakapan berbahasa meliputi mendengarkan, berbicara dan menulis dan pembelajaran yang berhubungan dengan seni sastra, seni tari, seni kuliner, seni batik tetapi juga pembelajaran kebiasaan adat setempat.Kebiasaan di dalam kampus, keluarga, masyarakat kampung, kota dan kebiasan apa saja yang tabu bagi masyarakat setempat.Seringkali terjadi bahwa ada hal-hal yang bagi masyarakat merupakan hal yang tidak bisa diterima namun bagi PPI itu adalah hal biasa sehingga menimbulkan salah pengertian.

\section{Adat Kebiasan Setempat, Penghindaran, dan Solusi}

Berikut ini contoh-contoh yang sering dialami PPI yang tinggal dalam jangka waktu lama dalam keluarga di Indonesia dengan kondisi dan situasi setempat yang berpotensi menimbulkan gangguan dan hal-hal yang harus dihindari antara lain masalah makanan, berjalan di trotoar, lingkungan yang kurang bersih, berada ditempat umum, berkendaraan, menyaksikan festival atau hari besar, bepergian ke pantai atau gunung, adat istiadat setempat, dan peraturan keluarga.

Menawarkan makan adalah salah satu bentuk keramahtamahan orang Indonesia, namun belum tentu semua makanan cocok apalagi bila baru beberapa hari datang. Begitu tiba di suatu tempat makanan adalah kebutuhan yang paling utama, ketidak cocokan makanan dalam satu sampai tiga minggu pertama dapat menyebabkan sakit perut, muntah atau keracunan yang dapat mengakibatkan sakit disentri, sakit typhus dan penyakit lain yang memerlukan perawatan 
intensif. Hal yang harus dihindari adalah makan yang berbumbu pedas dan berminyak.

Di negara maju orang suka berjalan sambil melihat disekitar karena fasilitas bagi pejalan kaki sangat bagus dan lebar. Jalanjalan di kota-kota di Indonesiabelum semuanya dilengkapi dengan trotoar bagi pejalan kaki. Trotoar yang ada banyak yang digunakan untuk berjualan pedagang kaki lima atau untuk parkir mobil. Dengan kondisi tersebut berjalan kaki harus ekstra hati-hati

Berada di tempat umum seperti seperti bandara, mall, transportasi umum dan pasar kewaspadaan dalam membawa tas, dompet, kamera, dan dokumen-penting menjadi prioritas utama. Selalu ada orang-orang yang tak bertanggungjawab, melakukan hal-hal negatif untuk mendapatkan keuntungan Demikian pula pada saat menyaksikan festival, pertemuan, karnaval dan peringatan hari besar atau berada di kawasan keramaian menyaksikan suatu pertunjukan juga tak lepas dari orang-orang yang tak bertanggungjawab. Pada saat orang-orang menyaksikan atraksi, perhatian akan tertuju pada atraksi sehingga terkadang lupa akan barang-barang yang dibawanya. Pada saat-saat tertentu para peserta festival atau karnaval beraksi dan pada saat itulah biasanya orang-orang yang tidak bertanggung jawab beraksi menunggu korbannya lengah atau sengaja mendorong, mendesak kerumunan, atau membuat gaduh untuk mendapatkan sesuatu.

Pergi ke pantai atau gunung menikmati pemandangan seyogyanya dilakukan pada pagi hari atau sore hari bila mau menginap, sehingga pada pagi hari bisa menikmati matahari terbit atau matahari terbenam.Naik gunung seyogyanya dengan orang yang sudah berpengalaman dan mengenal gunung tersebut dan mengenal pula apa yang diperbolehkan dan apa yang tidak diperbolehkan.

Berkendara, yaitu naik sepeda motor atau mengendarai mobil hanya diperolehkan bagi pelajar yang memiliki SIM internasional. Bagi salah satu organisasi internasional pertukaran pelajar apabila hal ini dilanggar maka yang bersangkutan akan dipulangkan ke negaranya (AFS - The Indonesian Foundation for Intercultural Learning, 2008, h. 49).

Hal lain adalah kurangnya pemahaman akan adat istiadat setempat sehingga terjadi kesalahpahaman. Salah satu contoh di sebagian besar masyarakat Indonesia masih berlaku aturan bahwa laki-laki dan perempuan hidup bersama tanpa nikah adalah tabu. Demikian pula berciuman dimuka umum bagi laki-laki dan perempuan yang bukan muhrim. Hal-hal semacam ini sangat perlu disampaikan kepada PPI. .

Dalam hal kepatuhan akan peraturan keluarga kadang terjadi sesuatu karena PPI yang kebanyakan orang Barat bisa menjadi sumber masalah Salah satu hal yang kurang dipahami adalah menghormati peraturan keluarga Pulang larut malam apalagi bagi anak perempuan Indonesia bukanlah hal yang lumrah.Seorang anak bagi keluarga Indonesia walaupun sudah dewasa dia tetaplah seorang anak dan orang tua bertangungjawab penuh. Hal ini yang kadang sulit dimengerti oleh orang Barat. Seseorang yang sudah berumur lebih dari 17 tahun di negara Barat sudah dewasa dan mempunyai kebebasan,namun tidak demikian halnya bagi orang Indonesia.

Masih banyak hal-hal lain yang disebabkan oleh perbedaan budaya maupun kebiasaan dalam keluarga dan masyarakat yang bisa menimbulkan kesalahpahaman dan akhirnya terjadi sesuatu yang tidak diinginkan. Solusi terutama masalah perbedaan budaya seringkali sulit dicapai karena masing-masing mengemukakan bahwa budayanyalah yang paling baik dan penyelesaian melalui budaya yang dibawanya adalah yang terbaik. Bahkan ketika sudah pulang sampai ke negara para peserta masih belum bisa menerima kalau perbedaan itu memang ada.Solusi yang tepat adalah menganalisa resiko dan memilih strategi yang paling tepat, menghindari situasi yang menimbulkan resiko, mencegah cara untuk menghindari, meminimalisir kesalahanan, jika sesuatu yang jelek terjadi mencari cara megurangi kesalahan tersebut(Posthuma, Richard, Garcia, Jaime,2008, h.4)

Antisipasi bencana bagi seseorang di tempat baru dimana orang tersebut jauh dari sanak saudara merupakan kebutuhan pokok. Indonesia belum termasuk negara yang fasilitas umumnya berstandar internasional sehingga banyak hal yang perlu diinformasikan, ditulis dan dipahami berkalikali. Pemahaman tentang perbedaan budaya dan tradisi ini ditulis dalam bahasa Indonesia, dan Inggris atau bahasa Indonesia dan bahasa asing lain sesuai dengan kebutuhan. Contoh- 
contoh diatas dapat dikembangkan dan dijadikan sebagai bahan ajar.Pola atau model yang diberikan latihan-latihan dalam bentuk pertanyaan tentang bacaan, latihan kosakata, skimming,scanning perlu diikuti dengan field trip sesuai dengan topik bacaan sehingga sehingga peserta PPBI atau program lain serupa betul-betul memahami hal-hal yang nampaknya sepele tetapi bisa menimbulkan bencana dan mengetahui apa yang harus dilakukan untuk meminimalisir bencana.
Secara lebih rinci manajemen resiko bagi PPI bisa dimulai dari pemberian informasi dan cara-cara menanggulangi bencana dan meminimalisir resiko yang terjadi dengan topik-topik sebagai berikut disertai dengan catatatn budaya dan catatan lain yang berhubungan dengan resiko yang terjadi. Secara lebih rincicontoh materi pembelajaran dapat disusun sebagai berikut:

Tabel 1: Contoh Materi Pembelajaran

\begin{tabular}{|c|c|c|c|c|c|c|}
\hline Topik & Sub Topik & $\begin{array}{l}\text { Manajemen } \\
\text { Resiko }\end{array}$ & $\begin{array}{l}\text { Catatan } \\
\text { Budaya } \\
\text { Setempat }\end{array}$ & $\begin{array}{l}\text { Kecakapan } \\
\text { Bahasa }\end{array}$ & $\begin{array}{l}\text { Bahasa untuk } \\
\text { Keperluan } \\
\text { Informasi }\end{array}$ & $\begin{array}{l}\text { Komponen } \\
\text { Bahasa }\end{array}$ \\
\hline $\begin{array}{l}\text { Musim } \\
\text { Kema- } \\
\text { rau dan } \\
\text { musim } \\
\text { Hujan }\end{array}$ & $\begin{array}{l}\text { Demam } \\
\text { Berdarah }\end{array}$ & $\begin{array}{lr}\text {-Hindari air } \\
\text { tergenang } \\
\text {-Gunakan obat } \\
\text { nyamuk } \\
\text { sebelum tidur } \\
\text { atau pasang } \\
\text { kelambu }\end{array}$ & $\begin{array}{l}\text { Jus jambu } \\
\text { merah } \\
\text { untuk } \\
\text { menambah } \\
\text { sel darah } \\
\text { merah }\end{array}$ & Membaca & $\begin{array}{l}\text { Mengidentifika- } \\
\text { si pokok pikiran }\end{array}$ & $\begin{array}{l}\text { Tata bahasa } \\
\text { Kosa kata } \\
\text { Pengucapan }\end{array}$ \\
\hline $\begin{array}{l}\text { Menge- } \\
\text { nalmasak } \\
\text { an } \\
\text { setempat }\end{array}$ & Diare & $\begin{array}{l}\text {-Hindari } \\
\text { masakan pedas } \\
\text {-Makan buah } \\
\text { dan roti pada } \\
\text { minggu pertama }\end{array}$ & $\begin{array}{l}\text { Daun } \\
\text { jambu biji } \\
\text { dan teh } \\
\text { pahit untuk } \\
\text { mengu- } \\
\text { rangi gejala }\end{array}$ & Menulis & $\begin{array}{l}\text { Membuat } \\
\text { ringkasan }\end{array}$ & $\begin{array}{l}\text { Tata bahasa } \\
\text { Kosa kata } \\
\text { Pengucapan }\end{array}$ \\
\hline $\begin{array}{l}\text { Keluarga } \\
\text { Indonesia }\end{array}$ & $\begin{array}{l}\text { Peraturan } \\
\text { keluarga }\end{array}$ & $\begin{array}{l}\text {-Hindari pulang } \\
\text { terlalu malam } \\
\text {-Memakai } \\
\text { pakaian yang } \\
\text { tertutup/sopan }\end{array}$ & $\begin{array}{l}\text {-Pulang } \\
\text { sesuai } \\
\text { aturan yang } \\
\text { disepakati }\end{array}$ & $\begin{array}{l}\text { Mendengar- } \\
\text { kan }\end{array}$ & $\begin{array}{l}\text { Mendengarkan } \\
\text { dialog dan } \\
\text { mengingat } \\
\text { kembali } \\
\text { informasi detil }\end{array}$ & $\begin{array}{l}\text { Tata bahasa } \\
\text { Kosa kata } \\
\text { Pengucapan }\end{array}$ \\
\hline $\begin{array}{l}\text { Nonton } \\
\text { Malang } \\
\text { Tempo } \\
\text { Dulu }\end{array}$ & $\begin{array}{l}\text { Waspada di } \\
\text { tempat } \\
\text { keramaian }\end{array}$ & $\begin{array}{l}\text {-Hindari } \\
\text { memakai } \\
\text { barang-barang } \\
\text { berharga } \\
\text {-Bawa uang } \\
\text { secukupnya }\end{array}$ & $\begin{array}{l}\text {-Pergi } \\
\text { bersama } \\
\text { teman- } \\
\text { teman } \\
- \\
\text { Mengenaka } \\
\text { n batik } \\
\text { atau busana } \\
\text { tempo } \\
\text { dulu- }\end{array}$ & Berbicara & $\begin{array}{l}\text { Bertukar } \\
\text { informasi } \\
\text { tentang Malang } \\
\text { Tempo Dulu }\end{array}$ & $\begin{array}{l}\text { Tata bahasa } \\
\text { Kosa kata } \\
\text { Pengucapan }\end{array}$ \\
\hline
\end{tabular}

Contoh diatas dapat diperluas dengan berbagai modifikasi. Kecakapan bahasa dapat diintegrasikan menjadi dua (mendengarkan dan berbicara), tiga(mendengarkan, berbicara dan membaca) atau empat kecakapan (mendengarkan, berbicara, membaca dan menulis) sesuai dengan kebutuhan. Demikian pula komponen catatan budaya, manajemen resiko, topik dan sub topik. Kolom-kolom diatas juga bisa ditambah dengan pendekatan pembelajaran yang akan dipakai misalnya Notional Functional, Communicative Approach, Contextual Teaching and Learning, Content Language Integrated Learning(CLIL, Scientific Approach atau integrasi dari pendekatanpendekatan tersebut demikian pula dalam hal tujuan, media dan ilustrasi(Muhrofi-G, Kun A, 2014, h.156 ) 


\section{SIMPULAN}

Manajemen resiko penting untuk diketahui, dipelajari dan dipraktekkan bagi penyelenggara program internasional maupun para peserta karena berhubungan dengan keselamatan dan kesehatan. Salah satu cara yang tepat adalah dengan memasukkan manajemen resiko dalam pembelajaran kecakapan bahasa dan budaya baik itu dalam program PPBI maupun program internasional lain.Pembelajaran ini juga akan banyak memberikan manfaat pembelajaran budaya lokal yang berhubungan dengan keselamatan dan kesehatan. Budaya tersebut akan menjadi nilai tambah yang perlu dilestarikan. Banyak hal tentang budaya yang sebetulnya sudah kita punyai namun karena kurangnya usaha untuk menerapkan dan menuliskannya sehingga catatan -catatan tersebut lambat laun hilang.

Keberhasilan program internasional akan banyak memberikan manfaat bagi pengembangan bahasa dan budaya Indonesia di tingkat internasional, dan manajemen resiko merupakan aspek yang harus menjadi skala prioritas. Apabila program-program internasional berhasil dengan baik maka dengan sendirinya merupakan promosi yang baik pula. Untuk mendukung hal tersebut harus ada kerjasama antara penyelenggara, keluarga yang ditempati, organisasi-organisasi lokal yang menjadi mitra dan semua pemangku kepentingan hendaknya memahami manajemen resiko.

\section{DAFTAR PUSTAKA}

Baltzan, Philip dan Haag. 2009. dalam Oroian. M, 2011. Contributions to a Possible Risk Model for Tourism Industry in Romania. Diakses dari http://riscurisicatastrofe.reviste.ubbcluj.ro/Volume/X Nr 92011 h.12

Cetak Biru Komunitas Sosial Budaya(Socio-Cultural Community Blue Print) ASEAN 2010.Cetakan ke 2. Direktorat Jenderal kerjasama ASEAN Kementerian Luar Negeri Republik Indonesia

Direktorat Ketenagaan Republik Indonesia 2008.

Goode, Sockalingam,Brown and Jones.2000, dalam Olmer dan Ali.2011. The Effect of Culture Integrated Language Courses on Foreign Language Education.US-China Education Review. ISSN 1548-6613 March, 2011Vol.8 No.3p-257-263.Diakses dari academia.edu/824798

Lemmet, Silvia dan Hopkins, KCMG. 2008 .United Nations Environment Programme, 2008 Disaster Risk Management for Coastal Tourism Destinations Responding to Climate Changepdf.Adobe Reader 20. Diakses dari www.unep.fr

Mc.Instosch.Goeldner and Ritchie.1995.(7th edition) Tourism: Principles, Practices and Philosophies. New York : John Wiley and Sons, Inc

Mehisto, Marsh and Frigols,2012. Uncovering CLIL(5th edition). Oxford : Macmillan Book for Teachers

Muhrofi-G Kun A, 2014. Local-Load based english instructional materials development for promoting tourist attraction of East Nusa Tenggara. Jurnal Pendidikan Ilmu Bahasa Volume 01 No.03 September 2014 (152-158). Program Studi Pendidikan Bahasa Inggris Pascasarjana Universitas Nusa Cendana

Pangestu, Mari Elka. Pidato Menteri Pariwisata Ekonomi Kreatif, 13 Mei 2014 Munas Hildiktipari Bandung

Posthuma, Richard, Garcia, Jaime.2008. Expatriate Risk Management : Keeping EmployeesSafe and Healthy, Diakses dari_academics.utep.edu/LinkClick.aspx

Tomalin, Brian 2008.Culture the Fifth Language Skill. Diakses dari www.teachingenglish.org.uk/article culture-fifth language skill 